\title{
EDITORIAL GENDER AND HEALTH: AN INTRODUCTION
}

\section{Naila Kabeer and Alanagh Raikes}

While health has always been seen as an integral aspect of development planning, the significance attached to it has varied according to the debates about development in the wider sense. Currently, there is a tension between those who treat health provision as the welfare arm of structural adjustment policy, those who treat it as a form of human resource investment - and hence critical to the process of economic recovery - and those who see it an end in itself, an essential component of human welfare.

How these tensions are resolved will determine not only what proportion of national and international budgets are made available to the health sector, but also the terms on which health provision is made available. In other words, if health is seen as an end in itself, then the emphasis in health provision will be on those whose needs are most compelling. If, on the other hand, health is seen as a means to ensure higher productivity, provision is likely to be made on the basis of contribution to economic growth.

The papers in this collection, while addressing different aspects of the issue of health, share the position that health is an end in itself and therefore one of the goals of health policy must be to establish the most effective means by which health care can be effected within the community. However, it is our contention that such a position is not incompatible with one that is concerned with economic development in its broadest sense. It is being increasingly recognised that human labour is one of the key scarce resources for many economies. Clearly, the quantity of human labour is one dimension of this constraint. But we believe that there is a great deal to be gained from a concern with what economists call the 'quality' of human resources and which we interpret as the ability of people to lead healthy and active lives. Within such a perspective, the absence of disease is only one criteria for judging the effectiveness of health policy. Other criteria are reliability, responsiveness as well as the more intangible quality of respect accorded to those who use health services so that 'clients' become 'partners' in shaping how health needs are to be addressed.

The primary health care approach appeared to meet some of these criteria. It sought to devolve responsibility away from the professionals and to return it to the community; to decentralize health provision; finally it sought to stress preventive health care, hence focusing on the causes of ill-health, rather than curative care, which mainly addressed the conditions of ill-health.

However, the notion of the 'community' it sought to incorporate was never clearly spelt out. Communities, after all, are not abstract and homogenous groups of individuals, but rather women, men and children who have different health needs and play different roles in assuring that these needs are met. A gender analysis of research and experience in health provision in the Third World (and also in the First) suggests that women, particularly poor women, have been frequently overlooked in the design and implementation of health policy. The reasons for this vary. These biases occur because much of the male-dominated medical establishment has tended to identify health needs according to its own preconceptions and biases. Women's own health concerns have often been overlooked and they are seen primarily in their roles as mothers and wives. However, even in Mother-Child Health programmes, much of the $\mathrm{MCH}$ budget tends to be allocated to child health. The argument appears to be that women will benefit from improved child health. This is of course true, but only part of the picture. It is equally the case that children's chances of survival and welfare are likely to be improved if their mothers can lead healthy, active lives. In other words, there are biological and social synergies between the health of mother and child which require attention to be given to both, in the interests of both.

There is a further reason for taking specific account of women in the formulation of health policy and that is their disproportionate role in the provision of health care. Health policies would be more effective if they were to acknowledge this explicitly so that different levels of health provision could be planned with their true implications for 'community participation' taken into account. Leslie's article directly addresses this question. It follows on from her earlier work which examined the extent to which primary health care and the 'child survival' strategies relied heavily on uptake at the household level by the primary health agent. Much of the failure of PHC to effect high levels of community participation could have been avoided if it had 'named' women as the relevant agents of the community and examined in greater detail their capacity to respond to PHC messages. The key constraint that prevented women from participation appears to have been one of time. Given the multiple demands on women's time in 
production and reproduction - this is particularly true of poor women - and the absence of alternative caretakers within the family, households have frequently been unable to accommodate the additional demands of primary health care interventions.

However, there does not appear to have been any concerted effort to address these aspects of community participation. Instead, the issue of women's time and energy takes on increasing urgency as a number of development agencies appear to be narrowing down what counts in the health agenda. From broad based primary health care programmes, aid agencies such as the USAID, WHO and UNICEF are successively narrowing down their health focus to more 'vertical' strategies such as those of the child survival technologies. There is now also a heightened focus on intensive breastfeeding. Clearly, in situations of resource scarcity, priorities in health interventions have to be made. Intensive breastfeeding carries immense benefits for an infant's health, but it is not a costless strategy.

Joanne Leslie's article draws our attention to the time costs that may be incurred by poorer women in the Third World in attempting to implement intensive breastfeeding. She also offers a series of analytical distinctions to focus attention more clearly on the demands made on a mother's time by different categories of health care. She distinguishes between the discretionary character of preventive care against the more compelling character of curative and crisis management forms of health care. She also distinguishes between health interventions which require women's presence and those which can be dealt with by an another member of the family and finally between different locations of health services.

The issue of community participation is also addressed in Alice Welbourn's article. She is concerned with methods to ensure that communities are drawn into the process by which health needs are identified and people in greatest need are properly addressed. She recounts her experience in using and developing the methods of rapid rural appraisal (RRA) in training health workers in a number of Third World communities. An important insight from her work is that such techniques will give health workers not only more empathetic ways of communicating with the poor, but also allow them to explore more sensitive issues which would otherwise never get mentioned. Her experience suggests that had health policy evolved with more attention to the use of RRA, the notion of communities undifferentiated by class and gender would never have been allowed to inform primary health care approaches.

We have noted earlier the male dominance of the medical establishment. However, the gender composition of health service delivery changes quite radically as one moves down its pyramidal structure.
Alanagh Raikes' article addresses some of the problems which stem from this aspect of gender relations in the health field. Her article looks at women as providers of health care, arguing that the current economic crisis has thrown greater emphasis on the lower paid and less formal health workers who tend to be female. Often it is the lower paid female health workers who are given the task of supporting and working with the community and thus the viability of PHC programmes very often depends on these women who are seriously underresourced. They receive unrealistic wages, irregular travel allowances, are often over-burdened with work and furthermore have little voice in the decision making processes. They are often squeezed into the production of poor quality health care services, into selling drugs or diagnosing and treating patients illegally as well as being directly involved in harmful family planning practices. She argues for recognition of the problems faced by lower level female health workers as well as a research agenda to address this issue.

The following articles are concerned with women's health as a concern for health policy. Jerker Edstrom's deals with an aspect of women's health which has only recently begun to receive specific attention of the international health community: maternal mortality. It traces the way in which indicators for women's health have evolved in the health community and sees the new concern with maternal mortality as the product both of increased recognition of women's role in development as well as of the synergies between mother and child health. Examining the effects of different variables on maternal mortality rates, Edstrom persuasively demonstrates that it cannot be considered in isolation from the broader context of women's lives. He concludes by identifying a number of indicators which might capture this more holistic view of women's health status.

Gill Gordon and Charlotte Kanstrup are concerned with a dimension of women's health which has not yet received much recognition in official health agendas. They call sexuality the 'missing link' in women's health. The urgency given to tackling AIDS has demonstrated as never before the link between sexual practice and health concerns, but sexuality also features in a variety of circumstances to affect women's health. They suggest that while women's biology makes them more vulnerable to the negative consequences of sexuality, it is their lack of self-determination which poses the problem for their health and wellbeing. Pregnancy in the context of inadequate health facilities puts women at risk of complications, ill-health, injury or death. Another sexually-related health risk is posed by female circumcision. Finally, all sexuallytransmitted diseases, including HIV, are more easily transmitted from men to women than from women to men. Gordon and Kanstrup call for more work within 
communities and families to identify options for promoting sexual health, but also point to the need to address the power relations between women and men within the community.

The final article in the collection details the experience of an innovative $\mathrm{NGO}$ in India as it moved from a traditional welfare approach towards women in the community to one which stressed their empowerment. Janet Price spent a number of years with SUTRA in Himachal Pradesh. She is concerned with empowerment as a process by which women identify their own needs rather than having to respond to priorities defined by an outside agency. Here again we find a number of issues emerge which conventional welfareoriented programmes have generally ignored. Many of these issues have health implications and many touch on the power relations of gender. Thus domestic violence, rape and alcholism were among those raised by the women and a campaign was organised to prohibit the opening of liquor shops because alcoholism was seen as underlying much of the violence against women.

Janet Price's article stresses again the point made by some of the other articles - that health problems cannot be viewed in isolation from the context in which they occur and that women's health problems cannot be divorced from the power relations of class and gender. Returning then to the idea of community participation, perhaps the joint message that these articles are seeking to impart is that communities are sites of struggle over the interpretation of whose needs will count. If community participation is to become a reality, it must seek to include those whose needs have been so systematically overlooked in most previous efforts. 